NBER WORKING PAPER SERIES

\title{
NETWORKS VERSUS MARKETS IN INTERNATIONAL TRADE
}

James E. Rauch

Working Paper 5617

\author{
NATIONAL BUREAU OF ECONOMIC RESEARCH \\ 1050 Massachusetts Avenue \\ Cambridge, MA 02138 \\ June 1996
}

This paper has benefited from discussions with Ross Starr. Comments by Jonathan Eaton and Walter Heller have also been helpful. I wish to thank James Harrigan and Shang-Jin Wei for generously supplying data and Donald McCubbin for outstanding research assistance. Previous drafts were presented at the National Bureau of Economic Research, the World Bank, and the following universities: British Columbia, Rice, Texas at Austin, California at Los Angeles, City of New York Graduate Center, Princeton, New York, Maryland at College Park, Harvard, Columbia, and Queens College of City of New York. Financial support was provided by NSF grant \#SBR 94-15480. I am responsible for any errors. This paper is part of NBER's research program in International Trade and Investment. Any opinions expressed are those of the author and not those of the National Bureau of Economic Research.

(C) 1996 by James E. Rauch. All rights reserved. Short sections of text, not to exceed two paragraphs, may be quoted without explicit permission provided that full credit, including $($ ) notice, is given to the source. 
NBER Working Paper 5617

June 1996

\title{
NETWORKS VERSUS MARKETS IN \\ INTERNATIONAL TRADE
}

\begin{abstract}
I propose a network/search view of international trade in differentiated products. I present evidence that supports the view that proximity and common language/colonial ties are more important for differentiated products than for products traded on organized exchanges in matching international buyers and sellers, and that search barriers to trade are higher for differentiated than for homogeneous products. I also discuss alternative explanations for the findings.
\end{abstract}

James E. Rauch

Department of Economics

University of California, San Diego

La Jolla, CA 92093

and NBER 


\section{Introduction}

It is well known that very few manufactured (as opposed to primary) commodities are traded on organized exchanges. It is also well understood that the heterogeneity of manufactures along the dimensions of both characteristics and quality interferes with the ability of their prices to signal relative scarcity. I argue that this uninformativeness of prices prevents "globally scanning" traders from substituting for organized exchanges in matching international buyers and sellers of differentiated products. Instead connections between sellers and buyers are made through a search process that because of its costliness does not proceed until the best match is achieved. This search is strongly conditioned by proximity and preexisting "ties" and results in trading networks rather than "markets".

This paper will explore the consequences of this network/search view at a macro level by examining world trade flows. In a companion paper (Rauch 1996) I explore the consequences of this view at a micro level by examining trade behavior, institutions, and policies in a partial equilibrium context. Section $I$ of this paper expands the argument adumbrated in the previous paragraph sufficiently to allow for empirical application. Section III uses a gravity model of international trade to see if proximity and common language/colonial ties are more important for differentiated products than for products traded on organized exchanges in matching international buyers and sellers. Section IV examines whether differentiated products tend to be less traded than homogeneous products, indicating that search costs are acting as barriers to trade. Section $\mathrm{V}$ considers alternative explanations, not based on the network/search view, for the findings in the preceding two sections. Conclusions and suggestions for further research are presented in 
Section VI.

\section{Organized Exchanges, Reference Prices, or Neither}

In the empirical work below I will divide intemationally traded commodities into three groups: those traded on organized exchanges, those not traded on organized exchanges but nevertheless possessing what I shall call "reference prices", and all other commodities. In this section I will give the theoretical motivation for this tripartite division.

Let us first consider why some commodities are traded on organized exchanges and others are not. The conventional wisdom is that there is a cost to setting up "markets" (organized exchanges) that is independent of the volume of transactions, and that this non-convexity will not allow a market to open if the expected volume of transactions at the price expected to prevail in equilibrium is too small.' For the sake of concreteness, let us attempt to apply this conventional wisdom to two commodities at the three-digit level of the Standard International Trade Classification (SITC), which is the least disaggregated level for which I will attempt to categorize commodities in the empirical work below. The two commodities are Footwear (SITC 851) and Lead (SITC 685, not to be confused with Lead Ores and Concentrates, SITC 2874). Suppose we use the dollar values of international trade in 1990 between the 63 countries in my sample below to indicate the "thickness" of the markets in these commodities, admitting that this is a bad proxy because it excludes domestic trade and does not account for the average size of

'Much to my surprise, I could not find a formalization of this "conventional wisdom" in the literature. The closest I found is Heller (1993). Market formation involves set-up costs in his model, but his focus is on coordination failure where it is mutually profitable to open markets in complementary commodities but not to open one of them individually. 
transactions. The figures are $\$ 27.3$ billion for Footwear and $\$ 1.3$ billion for Lead, of which nearly 90 percent is Lead and Lead Alloys, Unwrought (SITC 6851) as opposed to Lead and Lead Alloys, Worked (SITC 6852). Unwrought lead is traded on the London Metal Exchange while footwear is not listed on any organized exchange. This information appears to contradict the conventional wisdom on formation of organized exchanges. However, one could argue that "footwear" is not a well-defined commodity and needs to be disaggregated into various types of shoes, each one of which may have a volume of transactions smaller than that of lead. As we know, in the limit this process of disaggregation leads to shoes for which there is only one supplier: shoes are "branded" or differentiated products.

Without necessarily endorsing this argument, let us explore it further by contrasting Footwear with Polymerization and Copolymerization Products (SITC 583). 1990 international trade in these chemicals for the 63 countries in my sample amounted to $\$ 47.6$ billion. Like Footwear, they are not listed on any organized exchange, perhaps because they can be disaggregated into types for each of which the market is too "thin". Does this mean that Polymerization and Copolymerization Products should be treated in the same way as Footwear in the empirical analysis below?

The answer is no. Polymerization and Copolymerization Products are not "branded": prices can be quoted for these products without mentioning the name of the manufacturer, and these "reference prices" are found to be sufficiently useful by industry actors to be worth quoting in trade publications. For example, a price per pound of Polyoxyethylene Sorbitan Monostearate is quoted weekly in Chemical Marketing Reporter on the basis of surveys of suppliers. Abstracting from transportation costs, it is then possible for traders to assess the profitability of 
shipping polymerization and copolymerization products between any two countries solely on the basis of the prices prevailing at the ports of those two countries. One or more traders specialized in a given one of these chemicals can keep informed of its prices around the globe and perform intemational commodity arbitrage, matching distant buyers and sellers just as would traders on an organized exchange. As far as empirical analysis of matching international buyers and sellers is concerned, then, the reason to treat commodities traded on organized exchanges differently from commodities that only have reference prices is that we know the former have specialized traders that centralize price information while the same is only potentially true for the latter.

Shoes, on the other hand, do not have reference prices. Any observed price at another location must be adjusted for multidimensional differences in characteristics, and the adjustment depends on the varieties of shoes available at that location and the distribution of consumer preferences over varieties at that location. I claim that these informational demands are too great to permit international commodity arbitrage, ${ }^{2}$ and therefore traders will instead engage in a sequential search for buyers/sellers that terminates when some "reservation match" is achieved. This search is facilitated by proximity and common language, and by any contacts who "know the market". Of course the trader's network of contacts will also be strongly influenced by proximity and common language. Discussing "psychological barriers" to trade, Nothdurft (1992, pp. 39-40) states, "Typically, trade begins close to home and then, as experience and confidence grows, expands 'like rings in the water,' as one official of the Stockholm Chamber of Commerce

\footnotetext{
${ }^{2}$ Here I find it helpful to have in mind Hahn's (1971) definition of markets as activities that transform "named" goods into "anonymous" goods. One could argue that the "anonymity" provided by the price system is what makes international commodity arbitrage possible. It is not possible for "branded" (named) commodities because they have not been transformed into anonymous commodities by "markets" (organized exchanges) or by other means.
} 
put it."

For the purposes of the empirical work below, we can summarize the discussion of this section as follows. Possession of a reference price distinguishes homogeneous from differentiated products. Homogeneous commodities can be further divided into those whose reference prices are quoted on organized exchanges and those whose reference prices are quoted only in trade publications. The network/search model should apply most strongly to differentiated products and most weakly to products traded on organized exchanges, with its applicability to other homogeneous products unclear. Thus proximity and common language should have the greatest effects on matching international buyers and sellers of differentiated products, and search costs should act as the greatest barrier to trade for differentiated products. These hypotheses will be examined in sections III and IV, respectively.

\section{Evidence From a Gravity Model of Trade}

\section{A. The Gravity Model}

The standard (indeed, the only) empirical framework used to predict how countries match up in international trade is the gravity model. This model takes its name from the prediction that the volume of trade between two countries will be directly proportional to the product of their economic masses (as measured by GDP or GNP) and inversely proportional to the distance between them. As Harrigan (1994) and others have pointed out, at least two different theoretical

${ }^{3}$ It is tempting to extend this metaphor and suppose that, with the passage of time, the "rings in the water" will flatten out and disappear. Perhaps this is conceivable in a world where the varieties of differentiated product remain unchanged for long periods. In fact, product life cycles even for "low-tech" goods like shoes are quite short so that the search for buyers/sellers is constantly being renewed (see, e.g., Gereffi and Korzeniewicz 1990). 
foundations can be given for gravity models of trade: the monopolistic competition model and what Harrigan calls the Armington-Heckscher-Ohlin-Vanek model. The careful empirical work of Hummels and Levinsohn (1995) led them to conclude (p. 828) "that something other than monopolistic competition may be responsible for the empirical success of the gravity model," but the Armington-Heckscher-Ohlin-Vanek model is not strongly indicated as an alternative.

Rather than discuss its possible microeconomic foundations, I would instead like to note that the gravity equation can be derived from the assumption that every country consumes its own output and that of every other country in proportion to its share of world demand. This leads immediately to the equation

$$
V_{i j}=s_{i} G D P_{j}+s_{j} G D P_{i} \text {, }
$$

where I have used the notation from Helpman (1987): $V_{i j} \equiv$ bilateral volume of trade between country $i$ and country $j$ and $s_{n} \equiv$ share of country $n$ in world spending. Since under balanced trade $s_{n}=G D P_{n} / \overline{G D P}$, where $\overline{G D P} \equiv$ world gross domestic product, then assuming balanced trade yields

$$
V_{i j}=2 G D P_{i} G D P_{j} / \overline{G D P}
$$

This is the basic gravity relationship, minus the inverse dependence of trade on distance. I would argue that it is most useful to view this relationship as a basic "null" or starting point for further analysis of trade rather than as something that itself needs to be explained. In other words, it will 
often be useful for "positive" theoretical and empirical work on trade to focus on explaining deviations from this relationship, just as normative work takes autarky as its starting point and measures gains from trade relative to autarky.

In the empirical work below I will estimate the gravity model separately for each of the three commodity groups distinguished in the previous section. Following the same reasoning that led to equation (1), we write

$$
V_{i j k}=s_{i} w_{j k} G D P_{j}+s_{j} w_{i k} G D P_{i}
$$

where $w_{n k}$ is the commodity $k$ share of country $n$ output. Substituting for $s_{n}$ as before yields

$$
V_{i j k}=\left(w_{i k}+w_{j k}\right) G D P_{i} G D P / \overline{G D P}
$$

If $w_{n k}$ varies across $n$, due for example to comparative advantage, then $w_{i k}+w_{j k}$ is not constant for a given $k$. In the final gravity model specifications below I will assume that $w_{i k}+w_{j k}$ is absorbed into a multiplicative error term.

Following the usual gravity specification, I assume that factors that aid or resist trade cause deviations from (4) multiplicatively. In addition to distance and common language/colonial ties, we shall include the other factors aiding or resisting trade that were used by Frankel and co-authors in a series of papers on trading blocs (e.g., Frankel, Stein, and Wei 1993). They used the product of per capita GNPs in the belief that wealthier countries are more open to intemational trade. (They also used GNPs rather than the GDPs that appear in equations (1) - (4)). They added a dummy variable indicating when two countries are adjacent, which is important since the distance between Chicago and Mexico City, say, is a much less complete 
measure of the physical separation between the United States and Mexico than is the distance between Chicago and London of the physical separation between the United States and the United Kingdom. Finally, they added dummy variables indicating membership in two preferential trading blocs, the European Community (EEC) and the European Free Trade Association (EFTA).

I can now state the first gravity model to be estimated in subsection $\mathrm{C}$ below:

$$
\begin{gathered}
V_{i j k}=\alpha_{k}\left(G N P_{i} G N P_{j}\right)^{\beta_{k}}\left(P G N P_{i} P_{G N P_{j}}\right)^{\gamma_{k}} \operatorname{DISTANCE}^{\delta_{k}} \\
\times \exp \left(\epsilon_{k} A D J A C E N T+\zeta_{k} L I N K S+\eta_{k} E E C+\theta_{k} E F T A+u_{i j k}\right), \quad k=1,2,3,
\end{gathered}
$$

where $k=1$ denotes organized exchange commodities, $k=2$ denotes reference priced commodities, and $k=3$ denotes differentiated commodities, and PGNP denotes per capita GNP, DISTANCE equals the great circle distance between the principal cities of countries $i$ and $j$, $A D J A C E N T$ takes the value of one if countries $i$ and $j$ share a land border and zero otherwise, LINKS takes the value of one if countries $i$ and $j$ share a language or colonial tie and zero otherwise, EEC and EFTA equal one if countries $i$ and $j$ are members of the European Community and European Free Trade Association, respectively, and zero otherwise, and $u_{i j k}$ is a Gaussian white noise error term associated with the dependent variable $V_{i j k}$. Taking natural logarithms of both sides yields

$$
\begin{gathered}
\ln V_{i j k}=\ln \alpha_{k}+\beta_{k} \ln \left(G N P_{i} G N P_{j}\right)+\gamma_{k} \ln \left(P G N P_{i} P G N P_{j}\right)+\delta_{k} \ln D I S T A N C E \\
+\epsilon_{k} A D J A C E N T+\zeta_{k} L I N K S+\eta_{k} E E C+\theta_{k} E F T A+u_{i j k}, k=1,2,3 .
\end{gathered}
$$


Equations (6) will be estimated by Ordinary Least Squares (OLS). ${ }^{4}$

The dependent variable $V_{i j k}$ is bounded below by zero, and some observations achieve this bound. Following Eaton and Tamura (1994), I also estimate a modified gravity model in which the right-hand side of equation (5) must achieve a minimum threshold value $a_{k}$ before strictly positive values of $V_{i j k}$ occur. One reason we might observe $a_{k}>0$ is economies of scale in transportation. The second gravity model to be estimated in subsection $\mathrm{C}$ below is then

$$
\begin{gathered}
V_{i j k}=\max \left[-a_{k}+\alpha_{k}\left(G N P_{i} G N P_{j}\right)^{\beta_{k}}\left(P G N P_{i} P G N P_{j}\right)^{\gamma_{k}} D I S T A N C E^{\delta_{k}}\right. \\
\left.\times \exp \left(\epsilon_{k} A D J A C E N T+\zeta_{k} L I N K S+\eta_{k} E E C+\theta_{k} E F T A+u_{i j k}\right), 0\right], \quad k=1,2,3 .
\end{gathered}
$$

Rearranging and taking natural logarithms of both sides yields

$$
\begin{aligned}
\ln \left(a_{k}\right. & \left.+V_{i j k}\right)=\max \left[\ln \alpha_{k}+\beta_{k} \ln \left(G N P_{i} G N P_{j}\right)+\gamma_{k} \ln \left(P G N P_{i} P G N P_{j}\right)+\delta_{k} \ln D I S T A N C E\right. \\
& \left.+\epsilon_{k} A D J A C E N T+\zeta_{k} L I N K S+\eta_{k} E E C+\theta_{k} E F T A+u_{i j k}, \ln a_{k}\right], \quad k=1,2,3 .
\end{aligned}
$$

Equations (8) will be estimated by maximum likelihood, where the likelihood function is constructed using what I call a threshold Tobit model. The details of the estimation procedure are given in Eaton and Tamura (1994, pp. 490-492).

Following the discussion in the previous section, the factors resisting or aiding trade in which we are most interested are DISTANCE and LINKS. We especially want to know how the effects of these factors differ across the three commodity groups: organized exchange, reference

${ }^{4}$ The reader might note that it is possible to rewrite equations (5) and (6), replacing the product of per capita GNPs with the product of populations, in which case the coefficient on the product of GNPs would equal $\beta_{k}+\gamma_{k}$ and the coefficient on the product of populations would equal $-\gamma_{k}$. 
priced, and differentiated. However, if these three commodity groups differ in their transportability, this will confound our interpretation of the differences in their distance effects. Ideally, then, we should add a variable for transportation cost of commodity group $k$ between country $i$ and country $j$. Unfortunately, we shall see in the next subsection that available data does not allow us to create such a variable. Instead we will compute a measure of transportability for each commodity group, and use these to more crudely correct distance effects for differences in transportability in subsection $\mathrm{C}$ below.

Equations (6) and (8) will be estimated separately for the years 1970, 1980, and 1990 in order to check that the results are not the artifact of any particular time period and to allow for changes in coefficients, especially on DISTANCE and LINKS, that might have taken place due (for example) to changes in transportation and communication technology. In light of the theory presented so far, in each of the three years we expect the following relationships to hold among the coefficients after correcting for differences in transportability across commodity groups: $\beta_{k}=1 \forall k,\left|\delta_{1}\right|<\left|\delta_{2}\right|<\left|\delta_{3}\right|$, and $\zeta_{1}<\zeta_{2}<\zeta_{3}$. The effects of DISTANCE and LINKS for reference priced commodities are expected to be intermediate because, with regard to matching international buyers and sellers, their homogeneity makes them like organized exchange commodities but their lack of organized exchanges makes them like differentiated commodities.

\section{B. Data}

The sample of countries used in the estimation below is listed in Table 1. They are the same 63 countries that were chosen by Frankel and his co-authors. This allows me to use their data for all of my right-hand side variables: GNP and per capita GNP (in current dollars), great circle distance between principal cities, and dummies for adjacency, common language/colonial 
links, European Community membership, and European Free Trade Area membership. ${ }^{5}$ Unlike Frankel et al., I use the World Trade Database of Statistics Canada as my source for bilateral trade. The World Trade Database is derived from United Nations COMTRADE data. Its advantages are (1) it is much cheaper, especially important given that data at the 4-digit SITC level are being used, and (2) special care was taken to insure that trading partners were correctly identified (as opposed to listing an entrepôt as the trading partner), mainly by making careful efforts to insure that exports of country $i$ to country $j$ of commodity $k$ equal imports of country $j$ from country $i$ of commodity $k^{6}$

As discussed in the previous section, commodities are classified into three categories: organized exchange, reference priced, and differentiated, at the three- and four-digit SITC level. Trade reported at a less disaggregated level was omitted. Fortunately, this accounted for only 0.1 percent of the total value of trade in my sample in each of the three years. Commodities were classified in the following manner. All commodities at the five-digit SITC level were classified by looking them up in International Commodity Markets Handbook and The Knight-Ridder CRB

${ }^{5}$ Frankel et al. also used dummies for "membership" in the geographic areas East Asia and Western Hemisphere. Including these dummies in the estimation below shrinks the coefficients on DISTANCE (in absolute value) and LINKS, as one would expect, but does so in a proportional way across all product categories so that the comparisons of these coefficients are virtually unchanged. I prefer to exclude these dummies because they compound the problem of interpretation presented by DISTANCE: when comparing their effects across product categories, one again needs to try to control for differences in transportability.

${ }^{6}$ This method will not catch coordinated false reporting. Rozanski and Yeats (1994, p. 126) note that falsification of statistics has been a problem for "trade in some products (particularly petroleum or commodities covered by international quota agreements)". Since under the "conservative" aggregation discussed below Petroleum (SITC 3330) accounts for a low of 22.4 percent (in 1970) and a high of 53.0 percent (in 1980) of total trade in organized exchange products in my sample (less under the "liberal" aggregation), it seems prudent to see how key results might change if it were omitted. This will be done in footnotes to the next subsection. 
Commodity Yearbook (to check for organized exchanges) and Commodity Prices (to check for reference prices, e.g., price quotations published in trade joumals such as Chemical Marketing Reporter). Classification of the next higher level of aggregation was then done according to which of the three categories accounted for the largest share (almost always more than half) of the value of its world trade. Since the World Trade Database does not report world trade by fivedigit SITC, the sum of 1980 U.S. General Imports and Exports from the U.S. Department of Commerce was used for this purpose. Because ambiguities arose that were sometimes sufficiently important to affect the classification at the three- or four-digit level, both "conservative" and "liberal" classifications were made, with the former minimizing the number of three- and four-digit commodities that are classified as either organized exchange or reference priced and the latter maximizing those numbers. An appendix listing all of the commodities used in the estimation below and their conservative and liberal classifications is available on request.

Table 2 gives the shares of organized exchange, reference priced, and differentiated commodities in the value of total trade in my sample. Not surprisingly, differentiated products accounted for most of world trade, and their share rose between 1970 and 1990. The temporary fall in 1980 can be explained by the huge increase in the price of petroleum, an organized exchange product, between 1970 and 1980. The share of organized exchange commodities is of course higher in the liberal than the conservative aggregation and the share of differentiated commodities is lower, while the reference priced share is consistently lower although it gains from the differentiated category and loses to the organized exchange category in the liberal aggregation.

The preferred method of computing commodity transportation costs is to use the ratio of 
the difference between the customs, insurance and freight (c.i.f.) and customs values to the customs value for imports. Unfortunately, data for c.i.f. and customs values of imports at the four-digit SITC level are readily available only for the United States (from the U.S. Department of Commerce). ${ }^{7}$ Moreover, the United States does not import all commodities from all countries in the sample, the subset of commodities with positive imports tending to shrink as the volume of trade with the partner country shrinks. I therefore decided to abandon construction of a variable measuring transportation cost between country $i$ and country $j$ of commodity group $k$ in favor of construction of a measure of "transportability" of commodity group $k$ based on transportation costs between the United States and Japan, from which the United States recorded positive General Imports for over 86 percent of four-digit SITC commodities in $1985 .^{8}$ When positive imports from Japan were not recorded, c.i.f. and customs data for nearby countries or countries a comparable distance away were used. ${ }^{9}$ To aggregate these insurance and freight percentages up to measures of transportability for the three commodity categories, the shares of each three- or four-digit SITC in the total value of trade in that commodity category were used as weights. Of course insofar as more transportable commodities tend to be traded more this procedure tends to

${ }^{7}$ I cannot rule out the possibility that a heroic and expensive effort could have uncovered comparable data for other countries in the sample, at least potentially allowing for computation of a true transportation cost variable rather than the measure of commodity "transportability" for which I settle.

${ }^{8}$ In section IV this measure of transportability performs quite well in explaining the extent to which commodities are traded rather than consumed or supplied domestically.

${ }^{9}$ Countries were defaulted to in the following order: Korea, Taiwan, Philippines, Thailand, Malaysia, Singapore, Indonesia, Chile, Brazil, New Zealand and Australia. My original intention was to use U.S. General Import data from 1980 since that is the middle of the sample period, but this data sometimes yielded negative transportation costs, apparently due to spurious inflation of customs values. 
bias the numbers downwards, but since only their relative values across commodity categories rather than their absolute values will be used this should not be important.

Table 3 shows the results of this procedure. We see that, except for the liberal aggregation in 1970 , the transportabilities of the organized exchange and reference priced commodity groups are quite close, while the differentiated product group tends to be roughly twice as transportable as the other two groups. It will therefore be important to try to correct for transportability when comparing the effects of distance on trade in differentiated products versus organized exchange and reference priced products.

\section{Results of Estimation}

Tables 4 - 6 give estimates of equations (6), the first gravity model above. It should be noted that no attempt was made to adjust for changes in classification of commodities by the three categories that may have occurred during the period 1970 - 1990. GNP data is not available for Hungary and Poland in 1970 , reducing the maximum possible number of observations in that year from $(63)(62) / 2=1953$ to $(61)(60) / 2=1830$. The number of observations consistently falls well below the maximum, mainly because many countries do not trade with each other in certain commodity groups or their trade is too small to be recorded. We shall see below that dropping these zero observations has substantial consequences.

Turning to the hypotheses advanced at the end of subsection $A$, we see that $\hat{\beta}_{k}$ is always significantly different from one. The main hypotheses fare much better. The coefficients on LINKS are always smaller for the homogeneous commodity groups than for the differentiated commodity group, although the coefficients for the reference priced group are smaller than the 
coefficients for the organized exchange group in 1970 and for the liberal aggregation in 1980.

Comparing distance effects for organized exchange and reference priced commodities, between which differences in transportability are not an issue, we see that the former are always smaller. Surprisingly, distance effects are smaller for organized exchange commodities than for differentiated commodities even without adjusting for differences in transportability.

There is reason to believe that the results reported in Tables 4 - 6 are more favorable to the main hypotheses I have advanced than is justified. Note that the number of observations declines, and thus the number of zero observations on $V_{i j k}$ increases, as one moves from organized exchange commodities to differentiated commodities. If zero observations tend to occur between countries that are far apart and do not share a common language/colonial tie, then omitting them will tend to reduce the estimated effects of DISTANCE and LINKS, and that reduction will be greatest for organized exchange commodities and least for differentiated commodities. With this in mind we turn to Tables $7-9,{ }^{10}$ which give the estimates of equations (8), the second gravity model above."

I find these estimates to be preferable on two grounds. First, they fit the gravity models of subsection $A$ better in the sense that $\beta_{k}$ is never significantly different from one in 1990 , is

\footnotetext{
${ }^{10}$ Observations are missing in these tables because sometimes both country $i$ and country $j$ did not report trade at all (or did not report trade with each other in the case of China and Taiwan), making it impossible to reconstruct trade between them. This mainly happened in 1990 due to lags in reporting.

${ }^{11}$ Because the estimates of the thresholds $a_{k}$ are positive (and statistically significant at the one percent level), the estimates of the coefficients $\beta_{k}, \gamma_{k}$, and $\delta_{k}$ converge only asymptotically to the estimated elasticities of the dependent variable with respect to the corresponding independent variables as the dependent variable approaches infinity. The estimated elasticities evaluated at the mean values of the dependent variables can be found by multiplying the coefficient estimates by $\left(\hat{a}_{k}+\bar{V}_{i j k}\right) / \bar{V}_{i j k}$, a quantity that never exceeds 1.001 .
} 
significantly different from one only for organized exchange commodities in 1980 , and is not significantly different from one in for differentiated commodities in 1970 . Second, the estimates show a consistent, if slight, "shrinking of the globe" that we would expect to observe given the improvements in communication and transportation that occurred between 1970 and 1990 . All of the coefficients on DISTANCE decrease in absolute value from 1970 to 1980 and again from 1980 to 1990, unlike in Tables 4 - 6 where they mostly increase in absolute value between 1980 and 1990.' ${ }^{12}$ (In Tables $4-6$ four of the six coefficients on LINKS are smaller in 1990 than in either 1980 or 1970 while this is true for five out of six in Tables $7-9.) .^{13}$

Turning to the main hypotheses, the coefficients on LINKS are always less for the homogeneous commodity groups than for the differentiated commodity group, but the coefficients for the reference priced group are always less than the coefficients for the organized exchange group, except for the conservative aggregation in $1990 .^{14}$ The most important change from Tables 4 - 6 is that the differences between the organized exchange group coefficients and

\footnotetext{
${ }^{12}$ As distance-sensitive costs fall as a percentage of all costs, elasticity with respect to distance itself falls (in absolute value).

${ }^{13}$ On the other hand, all of the coefficients on $A D J A C E N T$ increase dramatically from 1970 to 1980 and again from 1980 to 1990. Another strange aspect of the behavior of the adjacency effects is that when one splits the differentiated commodity group into more and less transportable subgroups, as I do below, the distance effect is larger for the less transportable group as expected but the adjacency effect is smaller, leading one to wonder how much transportability really affects the coefficients on $A D J A C E N T$. Given the erratic behavior of these coefficients I thought it prudent to reestimate Tables 7-9 omitting the variable ADJACENT and the (maximum of) 67 country pairs for which it equals one. There were no qualitative changes in any results pertaining to the main hypotheses, and the same "shrinking of the globe" is observed.

${ }^{14}$ Omitting Petroleum from the organized exchange group yields the following coefficients on LINKS for 1970, 1980, and 1990, reporting the conservative and liberal aggregations respectively: 1.170 and $1.150,1.141$ and $1.093,0.827$ and 0.874 .
} 
the differentiated group coefficients are much smaller. Comparing distance effects for organized exchange and reference priced commodities, we see that as in Tables 4 - 6 the former are always smaller. ${ }^{15}$ Unlike in Tables $4-6$, however, distance effects are larger for the homogeneous commodity groups than for the differentiated commodity group except in 1970 .

Since Table 3 indicates that differentiated commodities are roughly twice as transportable as organized market or reference priced commodities, adjustment of the distance coefficients for differentiated products is in order. The simplest way to do this is to estimate the sensitivity of these coefficients to differences in transportability within differentiated commodities, and use this estimate to compute what the coefficients would have been had differentiated commodities been as transportable as either organized market or reference priced commodities. To avoid greatly increasing the number of observations for which $V_{i j k}=0$ when producing this estimate, I simply split differentiated commodities at the median value of transportability into more and less transportable groups, and then estimate the gravity equation separately for each group. The resulting distance coefficients are reported in Table 10 , where $l$ denotes the less transportable group and $m$ denotes the more transportable group.

The adjustment of the distance coefficients for differentiated commodities in Tables 7 - 9 then proceeds as follows. Assume that the distance coefficients $\delta$ are additively separable functions of search costs and transportation costs. Maintaining the hypothesis that search costs are equal within a commodity category, $\delta_{l}-\delta_{m}$ leaves only the difference attributable to less versus more transportability. Now denote our measure of transportability by $t$, and denote

\footnotetext{
${ }^{15}$ Omitting Petroleum from the organized exchange group yields the following coefficients on DISTANCE for 1970,1980 , and 1990, reporting the conservative and liberal aggregations respectively: -0.678 and $-0.730,-0.666$ and $-0.648,-0.662$ and -0.636 .
} 
measures computed as in Table 3 for the less transportable group of differentiated products ( $t>$ median) and the more transportable group ( $t \leq$ median) by $t_{l}$ and $t_{m}$, respectively. If we choose the functional form $c \ln t$ for the transportation cost component of $\delta, \delta_{l}-\delta_{m}$ yields $c \ln \left(t / t_{m}\right)$ so that only relative values of $t$ will matter in the adjustments. We thus compute our estimate of $c$, the sensitivity of the distance coefficients for differentiated commodities to differences in transportability, using the formula $\left(\hat{\delta}_{l}-\hat{\delta}_{m}\right) / \ln \left(t / t_{m}\right)$. We can then compute what the distance coefficients for differentiated commodities in Tables 7 - 9 would have been had their transportability been equal to that of organized market commodities and reference priced commodities, respectively, by adding $\hat{c} \ln \left(t_{1} / t_{3}\right)$ and $\hat{c} \ln \left(t_{2} / t_{3}\right)$ to these coefficients, where $t_{k}$ are the appropriate numbers from Table 3. The results are reported at the bottom of Table 10.

With the exception of the liberally aggregated reference priced commodities in 1980 , the adjusted distance effects for differentiated commodities are larger than the distance effects for the homogeneous commodity groups. Note that by construction the differences between the coefficients at the bottom of Table 10 and the coefficients on DISTANCE in Tables $7-9$ for organized exchange commodities and reference priced commodities are equal to the differences in the search components of these coefficients.

While the evidence presented in this section supports the hypotheses that proximity and common language/colonial ties are more important in matching international buyers and sellers of differentiated products than homogeneous products, and also the hypothesis that proximity is least important for homogeneous products traded on organized exchanges, it does so only weakly. The differences in the coefficients on DISTANCE and LINKS are consistent in sign but 
small in absolute magnitude. ${ }^{16}$ The implications of this for the value of the network/search approach to trade in differentiated products will be discussed in the concluding section of this paper.

\section{Evidence from the OECD COMTAP Database}

In the previous section we considered evidence for the network/search view of trade in differentiated products that could be revealed by the contrast between the way countries matched up in international trade in these products versus more homogeneous products, especially those traded on organized exchanges. This view also has implications for the extent to which differentiated versus homogeneous products are traded at all, that is, for the shares of production of different products that are traded rather than supplied or consumed domestically. Let us consider a commodity that is sufficiently homogeneous to have a reference price, but for which no trader is able to keep sufficiently informed of prices around the world to engage in international commodity arbitrage. We suppose therefore that any trader who wishes to export (import) this commodity must search for a price that is sufficiently higher (lower) than the

\footnotetext{
${ }^{16}$ The natural way to construct a formal test of whether or not the coefficients in Tables 7-9 are significantly different across commodity groups is to estimate a pooled model. The error term $u_{i j k}$ would then presumably have a country-pair specific component that is constant across commodity groups, making a random effects specification appropriate. This is very difficult to combine with the maximum likelihood procedure for estimating the threshold Tobit model. Let us nevertheless suppose that in each year the coefficients are not significantly different. We can then ask, focusing on the conservative aggregation, what are the odds that the DISTANCE coefficients (after adjustment for differences in transportability) would consistently rank lowest for organized exchange products and highest for differentiated products (in absolute value) across all three decades, and what are the odds that the LINKS coefficient for differentiated products would rank consistently highest across all three decades? The answers are $(1 / 6)^{3}$ and $(1 / 3)^{3}$, respectively, both of which events are significant at the .05 level.
} 
domestic price to cover transportation. tariffs, and so on. I claim that this search will be much less costly than a search for buyers (sellers) of a differentiated product that are good "matches", because prices can vary along only one dimension while product characteristics can vary along many. Hence the barrier to trade in products with reference prices is smaller than the barrier to trade in differentiated products, ceteris paribus, and we expect a higher proportion of production of the former products to be exported and a higher proportion of their consumption to be imported.

To test this hypothesis we need data on trade that is matched with data on production. Unfortunately, trade data is collected according to the Standard International Trade Classification while production data is collected according to the International Standard Industrial Classification (ISIC). The Compatible Trade and Production Database (see Berthet-Bondet et al., 1988, for a description) converts trade data to an ISIC basis for the period 1970-1985 for the OECD only, and only for manufacturing industries (ISIC codes beginning with 3). Production data is disaggregated to the four-digit ISIC level only for 13 of the 22 OECD countries, which however account for 95.1 percent and 94.0 percent of total OECD manufacturing production in 1970 and 1985, respectively. ${ }^{17}$ A total of 82 industries are distinguished, of which one, Metal Scrap from Manufacture of Fabricated Metal Products (ISIC 3801), had to be dropped due to fragmentary data. The analysis below is therefore based on the total production, exports, and imports of the 13 reporting OECD countries for 81 manufacturing industries.

Using OECD data presents a problem that would not occur if we had data for the entire

${ }^{17}$ The 13 countries are Australia, Belgium-Luxembourg, Canada, Finland, France, Italy, Japan, Netherlands, Norway, Sweden, United Kingdom, United States, and West Germany. 
world, for which imports are identically equal to exports: it might matter whether we test the hypothesis that tradedness increases with reference pricing using the export share of production or the import share of consumption. In particular, the OECD tends to have a comparative advantage relative to the rest of the world in differentiated manufactures and a comparative disadvantage in homogeneous manufactures, perhaps because the former are more skill-intensive or technologically sophisticated, leading to a bias against my hypothesis when tested using the export share of production and in favor of my hypothesis when tested using the import share of consumption. I decided to simply use the average of the export share and the import share as my dependent variable: ${ }^{18}$

$$
S H A R E \equiv[\text { Exports/Production + Imports/(Production + Imports - Exports) }] / 2 .
$$

The computation of the percentage of each industry's output that is reference priced is complicated by the fact that production figures for more disaggregated levels of the ISIC are not available. I therefore used the 1979 U.S. Department of Commerce publication Correlation Between the United States and International Standard Industrial Classifications to match each ISIC to the corresponding four-digit U.S. SIC(s), and then classified each seven-digit U.S. SIC component as reference priced or not. I then aggregated up from the seven-digit level using output figures from the 1977 U.S. Census of Manufactures to estimate the percentage of each ISIC's output that is reference priced, where 1977 was chosen because it is the midpoint of the

\footnotetext{
${ }^{18}$ In 1970 the average of the export share of production across 81 commodities was 13.8 percent compared to 12.6 percent for the import share of consumption. The comparable figures for 1985 were 19.0 percent and 18.9 percent. Hence there is no comparative advantage revealed for the OECD relative to the rest of the world in manufacturing as a whole. However, the average absolute difference between the two shares was 3.3 percent in 1970 and 4.2 percent in 1985. Clearly these figures would be much larger if the OECD did not mostly trade with itself.
} 
period covered by the COMTAP database. For the purposes of this section I chose to use this estimate as a continuous explanatory variable rather than to classify each industry as reference priced or not. ${ }^{19}$

Transportability was estimated using the difference between c.i.f. and customs values of U.S. imports as in the previous section. Since the U.S. Department of Commerce does not produce trade data classified by ISIC, the transportability estimate for the largest U.S. SIC among those that make up the 4-digit ISIC was used. Where the largest was not available (e.g., because the Department of Commerce does not use it to record trade), a judgment was made concerning the SIC that is most representative of the ISIC.

Since our estimates of transportability and reference pricing do not change from year to year, estimation will be reported for the beginning and end years of the sample only. (Results are not qualitatively different for other years.) Table 11 gives descriptive statistics for transportability (TRANSPORT), reference pricing (PRICING), and SHARE. Note that the median for reference pricing is less than two percent: most manufacturing industries have essentially no reference pricing, indicating that the zero-one classification of commodities as reference priced or not in the previous section was not such a bad approximation, at least for manufactured commodities. The minimum and maximum for TRANSPORT correspond to Aircraft (ISIC 3845) and Cement, Lime, and Plaster (ISIC 3692), respectively. A comparison of the 1970 and 1985 values of SHARE shows a substantial increase in OECD openness during this

\footnotetext{
${ }^{19}$ As mentioned above, reference pricing is typically based on the availability of price quotations in U.S. trade publications based on surveys of U.S. wholesale markets. It follows that there is minimal scope for "reverse causation", where extensive international trade leads to more price quotation and a high estimate of reference pricing.
} 
period, as expected. I also computed simple and rank correlation coefficients between TRANSPORT and PRICING, obtaining 0.490 and 0.460 , respectively. These results are also in line with expectations.

Table 12 reports regressions of SHARE on TRANSPORT and PRICING. ${ }^{20}$ Because SHARE can only vary from zero to one but OLS can yield predictions outside this range, a logistic transformation of SHARE is used as the dependent variable. ${ }^{21}$ The results in the first and third columns are not favorable to the hypothesis that reference pricing reduces barriers to trade: TRANSPORT has a robustly negative effect on SHARE while the effect of reference pricing is statistically insignificant. It may be, however, that the effect of reference pricing on tradeability is being masked by industry characteristics that are correlated with reference pricing and affect tradeability but are not picked up by TRANSPORT. For example, concem with "freshness" may act as a barrier to trade for Manufacturing of Food, Beverages, and Tobacco (ISIC 31). To account for this possibility, eight dummy variables for ISIC $31-38$ (ISIC 39 is the omitted twodigit industry) are included in the second and fourth columns of Table 12. F-tests reject exclusion of these dummies at the one percent level in both 1970 and 1985 . We see that reference pricing does have a statistically significant effect on SHARE within a two-digit manufacturing industry.

How important is reference pricing in lowering barriers to trade within a two-digit

${ }^{20}$ Use of the logarithm of TRANSPORT leaves the results qualitatively unchanged.

${ }^{21}$ The transformation is $\ln [S H A R E /(1-S H A R E)]$. In 1985 the value of exports for Fur Dressing and Dyeing Industries (ISIC 3232) exceeded the value of production, presumably because of difficulties in translating from SITC to ISIC. I therefore dropped this industry, leaving 80 observations. Simply substituting imports for exports and retaining this observation does not qualitatively change the results. 
industry? Holding all other variables (including dummies) at their mean levels, we can compute the predicted value of SHARE for an industry with zero reference pricing and one hundred percent reference pricing using the formula $\exp (\hat{y}) /[1+\exp (\hat{y})]$, where $\hat{y}$ is the predicted value of the transformed dependent variable. The results are 0.077 and 0.233 in 1970 and 0.126 and 0.270 in 1985 , indicating that a change from no reference pricing to full reference pricing more than doubles the tradedness of an industry within a two-digit classification. The decrease in the effect of reference pricing between 1970 and 1985 is consistent with the "shrinking of the globe" found in the previous section. A similar decrease (in absolute value) is found for the effect of transportability within a two-digit industry: the elasticity of SHARE with respect to TRANSPORT, evaluated at the means, equals -0.96 in 1970 and -0.65 in 1985.

\section{Alternative Explanations}

I have examined evidence at the level of world trade flows in order to determine whether the theoretical considerations of section II make a difference at the aggregate level. Too often, the effects of imperfect information are discussed only at the micro level, with no sense of how or if they aggregate up to something observable at the macro level. Unfortunately, evidence at such an aggregate level allows for many altermative explanations. This evidence will ultimately have to be supplemented by case studies of trading and marketing practices for different types of products.

Many of the alternative explanations for the results in sections III and IV can explain only 
some of the results. ${ }^{22}$ Rather than try to discuss each one (and knowing that the reader can always think of more), I will discuss one alternative explanation that I find particularly compelling because it can explain all of the results. ${ }^{23}$ Suppose that firms develop their varieties of differentiated products to suit niches in their home markets. We suppose further that they do this not because they know more about their home markets than about foreign markets, which would again indicate an incomplete information structure where information about buyers is mediated by distance, but because positive transportation costs make this the best decision, ceteris paribus. This could explain why differentiated products tend to be less traded: there is less demand for them outside the country in which they are produced. Now suppose further that the similarity of foreign preferences to those in the home country falls with distance and rises with common language/colonial ties. This could explain why trade in differentiated products decreases more with distance and increases more with links than trade in homogeneous products: a geographic and linguistic application of the Linder hypothesis. ${ }^{24}$

\footnotetext{
${ }^{22} \mathrm{~A}$ good example is based on the natural resource intensity of organized exchange and reference priced products. It can be argued that this leads these products to be traded more extensively, and across greater distances (Kuwait and Saudi Arabia should not exchange much petroleum), but this alternative explanation cannot explain the lower coefficients on LINKS for these product groups. In any case, this argument should hold most strongly for countries that share a land border, yet the coefficients on ADJACENT in Tables 7-9 are always largest for organized exchange products and smallest for differentiated products. The fact that the coefficient on DISTANCE falls (in absolute value) when petroleum is omitted from the organized exchange group (see footnote 15 ) also casts doubt on this altemative explanation.

${ }^{23}$ On the other hand, there may be reasons to believe that the results would be stronger in the absence of certain countervailing influences. For example, we know that there are many preferential trading agreements for agricultural products based on colonial ties, and these should work to make the links effect larger for the homogeneous commodity groups.

${ }^{24}$ Of course production of similar varieties in nearby countries and countries with a common language/colonial tie would increase too, but this may just stimulate "intraindustry" trade rather
} 
While it is hard to believe that this altemative explanation is completely unrelated to the findings of sections III and IV, a clever study by Gould (1994) strongly suggests that it is not the whole story. He finds that immigration to the United States increases U.S. bilateral trade with the immigrants' countries of origin, that this "immigrant-link effect" is stronger for U.S. exports than for U.S. imports, and that the effect on exports exhausts itself for a much smaller number of immigrants than does the effect on imports. Taken together these results indicate that the most important effect of immigration on trade is through the establishment of business contacts, with a secondary effect through increased U.S. preferences for goods produced in the country of origin. By extension, the argument that preferences are mainly responsible for the findings of sections III and IV is undermined.

If the theory of section II has merit, the immigrant-link effect on exports should be greatest for differentiated products and smallest for homogeneous products traded on organized exchanges. Gould did in fact disaggregate his dependent variable, U.S. trade in manufactures from 1970 to 1986 (from the OECD COMTAP database used in section IV above), into what he called consumer and producer goods. The four-digit industries he lists in the former category tend to be less "priced" in the sense of section IV than those in the latter category. Gould reports (p. 310) that, "The immigrant information variable does not appear to be important in the producer imports equation."25

than decreasing trade. Moreover, this production of similar varieties allows extension of the alternative explanation to trade in producer goods as well as consumer goods.

${ }^{25}$ When Gould uses the logarithm of the immigrant stock as his explanatory variable, yielding a constant elasticity specification (also used by Head and Ries 1995 in their work on immigration and trade for Canada), it is significant in the consumer export equation but not in the equations for consumer or producer imports or producer exports. It should be noted that Gould's equations 


\section{Conclusions and Suggestions for Further Research}

In section III we saw that the differences in proximity and links effects across organized exchange, reference priced, and differentiated commodities, while in the direction predicted by the network/search view of trade in differentiated products, were quantitatively small. In section IV we saw that the effects of reference pricing on the extent of trade were present only within a two-digit industry. Are these results due to a small quantitative importance of networks and search in trade, or to an overestimation of the importance of "markets", leading to networks and search being very significant for homogeneous as well as differentiated products? The latter explanation is supported by the fact that the coefficients on LINKS consistently imply that countries that share a common language/colonial tie trade with each other products listed on organized exchanges more than twice as much as countries that do not. ${ }^{26}$ Once again, however, examination of more disaggregated data or even case studies of trader behavior will ultimately be needed to answer this question.

An important aim of this paper is to put networks and search on the agenda for the study of trade. One advantage of the network/search view of trade in differentiated products is that it helps to make sense of certain micro-institutional features of trade. In Rauch (1996) I show that a simple partial equilibrium search model yields economies of scope in search for buyers of differentiated products, which can help us understand the role of "social capital" in international

contain fixed effects for every U.S. trading partner, so the immigrant stock cannot be acting as a proxy for distance or common language/colonial ties.

${ }^{26}$ Since the value of this trade is dominated by grains, oil seeds, fuels, and both mineral and nonmineral raw materials such as metals, a preference-based explanation for this finding is highly implausible. 
trade and the viability of general trading companies such as Japan's sogo shosha. I also note that if search is subject to free-riding (through unintended information spillover) there may be a rationale for ubiquitous export promotion policies such as subsidized trade missions. More broadly, the network/search view of trade opens up space for greater consideration of the role of personal contacts and relationship-building in determining the geographic distribution of economic activity. This is the subject of many business press anecdotes but not much systematic economic analysis (see Egan and Mody 1992 for an exception).

Foreign Direct Investment (FDI) projects bear the same relationship to portfolio investments as differentiated products do to homogeneous products. Unfortunately, as far as I know it is impossible to obtain data on bilateral portfolio investment flows, making comparisons of the kind performed in section III impossible. Nevertheless, the importance of proximity for bilateral FDI flows could be seen as evidence in favor of the robustness of the network/search view as an approach to understanding economic transactions more generally, the transactions being in "differentiated projects" rather than differentiated products. Eaton and Tamura (1994) examine U.S. and Japanese bilateral FDI flows. They use regional dummies rather than distance, and find (p. 4), "Taking into account population, income, and factor endowments, both countries have deeper trade and investment relationships with countries in their respective regions than with the rest of the world." This finding is especially striking when one considers that most FDI is undertaken with the aim of penetrating the market of the host country, so that one should expect distance to have a positive effect on bilateral FDI flows given the proximity-concentration tradeoff.

A long-term goal for future research is formalization of the network/search view of trade 
in a general equilibrium model. It is possible that this could lead to many more empirical applications and more detailed predictions. We may, for example, be able to improve our analysis of the effects of distance and common language/colonial ties in mediating the economic impacts of trade liberalization agreements. ${ }^{27}$

${ }^{27}$ Leamer (1993, pp. 60-61) concluded that, "NAFTA is not a free trade agreement between Canada, the United States, and Mexico. It is really a free trade agreement between northem Mexico, California, and Texas." 


\section{References}

Berthet-Bondet, Claude, Derek Blades, and Annie Pin. 1988. The OECD Compatible Trade and Production Data Base 1970-1985. OECD Department of Economics and Statistics Working Paper No. 60 (November).

Eaton, Jonathan, and Akiko Tamura. 1994. "Bilateralism and Regionalism in Japanese and U.S. Trade and Direct Foreign Investment Patterns." Journal of the Japanese and International Economies 8: 478-510.

Egan, Mary Lou, and Ashoka Mody. 1992. "Buyer-Seller Links in Export Development." World Development 20 (March): 321-334.

Frankel, Jeffrey, Ernesto Stein, and Shang-jin Wei. 1993. "Continental Trading Blocs: Are They Natural, or Super-Natural?" National Bureau of Economic Research Working Paper No. 4588.

Gereffi, Gary, and Miguel Korzeniewicz. 1990. "Commodity Chains and Footwear Exports in the Semiperiphery." In William Martin, ed., Semiperipheral States in the World Economy (Westport, Conn.: Greenwood): 45-68.

Gould, David M. 1994. "Immigrant Links to the Home Country: Empirical Implications for U.S. Bilateral Trade Flows." Review of Economics and Statistics 76 (May): 302-316.

Hahn, Frank H. 1971. "Equilibrium with Transaction Costs." Econometrica 39 (May): 417-439.

Harrigan, James. 1994. "Scale Economies and the Volume of Trade." Review of Economics and Statistics 76 (May): 321-328.

Head, Keith, and John Ries. 1995. "Immigration and Trade Creation: Econometric Evidence from Canada." Faculty of Commerce, University of British Columbia (July).

Heller, Walter P. 1993. "Equilibrium Market Formation Causes Missing Markets." University of California, San Diego Discussion Paper No. 93-07 (February).

Helpman, Elhanan. 1987. "Imperfect Competition and International Trade: Evidence from Fourteen Industrial Countries." Journal of the Japanese and International Economies 1: 62-81.

Hummels, David, and James Levinsohn. 1995. "Monopolistic Competition and International Trade: Reconsidering the Evidence." Quarterly Journal of Economics 110 (August): 799-836.

Leamer, Edward E. 1993. "U.S. Manufacturing and an Emerging Mexico." North American Journal of Economics and Finance 4: 51-89. 
Nothdurft, William E. 1992. Going Global: How Europe Helps Small Firms Export

(Washington, D.C.: Brookings Institution).

Rauch, James E. 1996. "Trade and Search: Social Capital, Sogo Shosha, and Spillovers." Mimeo, Department of Economics, University of Califomia, San Diego.

Rozanski, Jerzy, and Alexander Yeats. 1994. "On the (In)accuracy of Economic Observations: An Assessment of Trends in the Reliability of Intemational Trade Statistics." Journal of Development Economics 44: 103-130. 
Table 1

\section{List of Countries Used in Gravity Equations}

\begin{tabular}{|c|c|c|c|}
\hline COUNTRY & MAIN CITY & COUNTRY & MAIN CITY \\
\hline Algeria & Algiers & Libya & Tripoli \\
\hline Argentina & Buenos Aires & Malaysia & Kuala Lumpur \\
\hline Australia & Sydney & Mexico & Mexico City \\
\hline Austria & Vienna & Morocco & Casablanca \\
\hline Belgium $^{a}$ & Brussels & Netherlands ${ }^{a}$ & Amsterdam \\
\hline Brazil & Sao Paulo & New Zealand & Wellington \\
\hline Bolivia & La Paz & Nigeria & Lagos \\
\hline Canada & Ottawa & Norwayb & Oslo \\
\hline Chile & Santiago & Pakistan & Karachi \\
\hline China & Shanghai & Paraguay & Asuncion \\
\hline Colombia & Bogota & Peru & Lima \\
\hline Denmark ${ }^{2}$ & Copenhagen & Philippines & Manila \\
\hline Ecuador & Quito & Poland & Warsaw \\
\hline Egypt & Cairo & Portugal $^{\mathrm{a}}$ & Lisbon \\
\hline Ethiopia & Addis Ababa & Saudi Arabia & Riyadh \\
\hline Finland $^{b}$ & Helsinki & Singapore & Singapore \\
\hline France $^{2}$ & Paris & South Africa & Pretoria \\
\hline Ghana & Accra & South Korea & Seoul \\
\hline Greece $^{2}$ & Athens & Spain & Madrid \\
\hline Hong Kong & Hong Kong & Sudan & Khartoum \\
\hline Hungary & Budapest & Sweden $^{\mathrm{b}}$ & Stockholm \\
\hline Iceland ${ }^{b}$ & Reykjavik & Switzerland ${ }^{b}$ & Geneva \\
\hline India & New Delhi & Taiwan & Taipei \\
\hline Indonesia & Jakarta & Thailand & Bangkok \\
\hline Iran & Tehran & Tunisia & Tunis \\
\hline Ireland $^{2}$ & Dublin & Turkey & Ankara \\
\hline Israel & Jerusalem & United Kingdom ${ }^{2}$ & London \\
\hline Italy² & Rome & United States & Chicago \\
\hline Japan & Tokyo & Uruguay & Montevideo \\
\hline Kenya & Nairobi & Venezuela & Caracas \\
\hline \multirow[t]{2}{*}{ Kuwait } & Kuwait & West Germany ${ }^{a}$ & Bonn \\
\hline & & Yugoslavia & Belgrade \\
\hline
\end{tabular}


Table 2

Shares of Commodity Categories in Value of Total Trade (Percent)

$\begin{array}{lllll} & & \underline{1970} & \underline{1980} & \underline{1990} \\ \text { Conservative } & \text { Organized Exchange } & 19.5 & 27.2 & 12.6 \\ \text { Aggregation } & \text { Reference Priced } & 24.0 & 21.3 & 20.3 \\ & \text { Differentiated } & 56.5 & 51.5 & 67.1 \\ & & & & \\ \text { Liberal } & \text { Organized Exchange } & 24.7 & 31.7 & 16.0 \\ \text { Aggregation } & \text { Reference Priced } & 21.8 & 19.5 & 19.5 \\ & \text { Differentiated } & 53.6 & 48.9 & 64.6\end{array}$

Note: Column total may not sum to 100.0 due to rounding error.

Table 3

Transportability of Commodity Categories

Liberal

Conservative

Aggregation

$\begin{array}{lrrrr} & \underline{1970} & \underline{1980} & \underline{1990} \\ \text { Organized Exchange } & 15.59 & 12.45 & 13.51 \\ \text { Reference Priced } & 13.06 & 12.19 & 12.05 \\ \text { Differentiated } & 6.58 & 6.40 & 5.88\end{array}$

Aggregation

$\begin{array}{lrrr}\text { Organized Exchange } & 16.04 & 12.67 & 13.89 \\ \text { Reference Priced } & 11.24 & 11.03 & 10.74 \\ \text { Differentiated } & 6.51 & 6.38 & 5.86\end{array}$

Note: Based on insurance and freight as percent of customs value of U.S. imports from Japan or comparably distant country. Complete description of computation in text. 


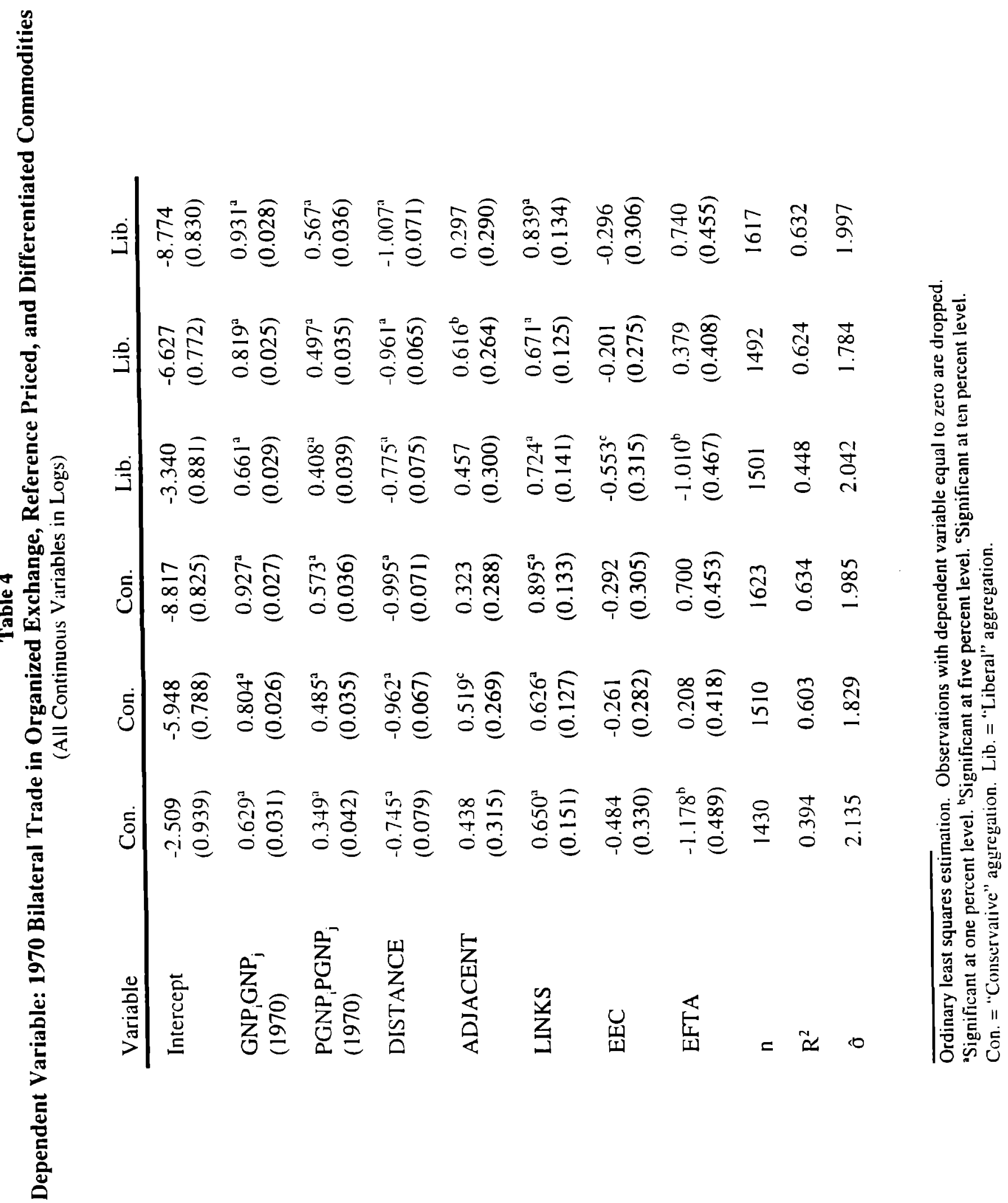




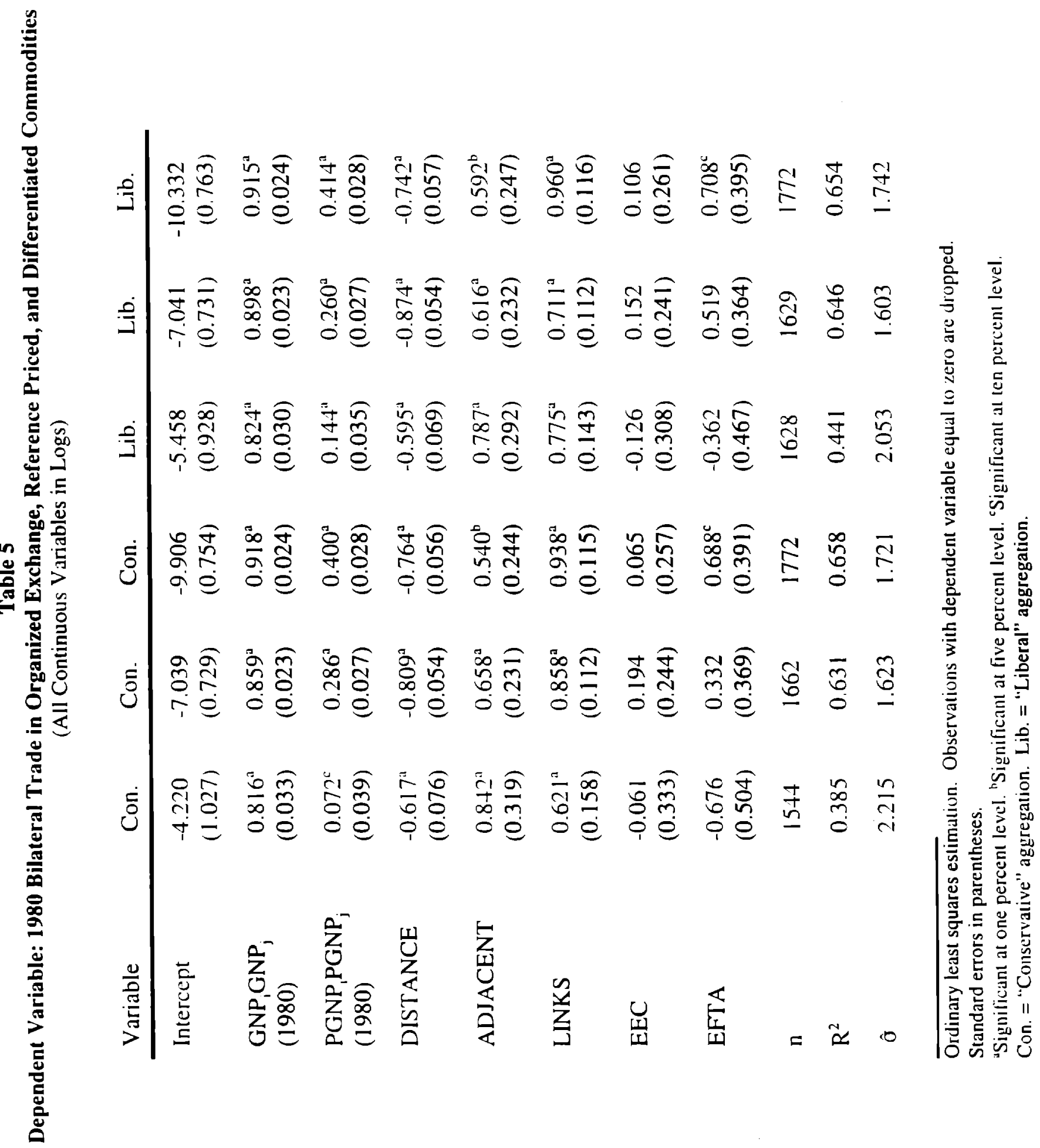




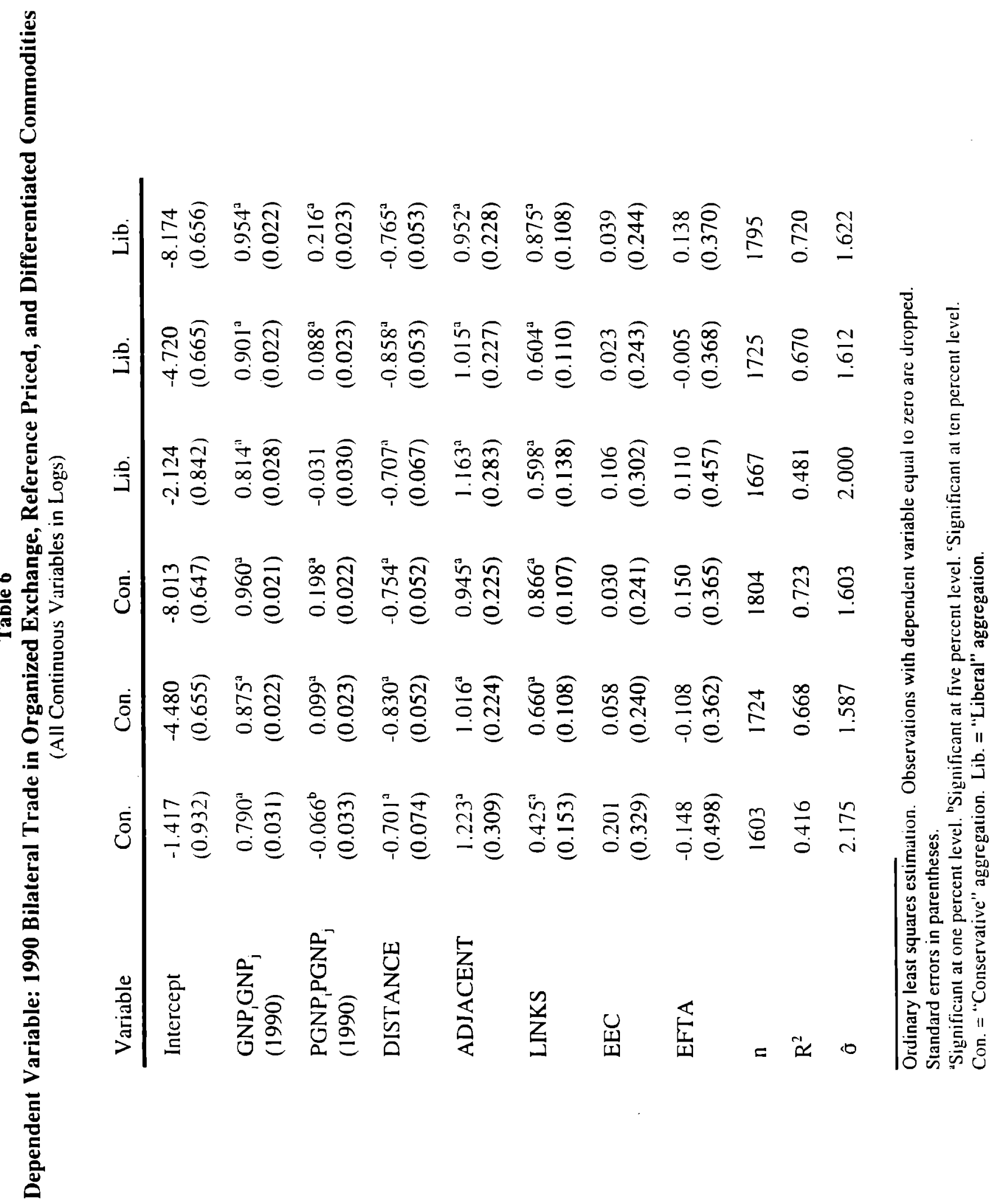




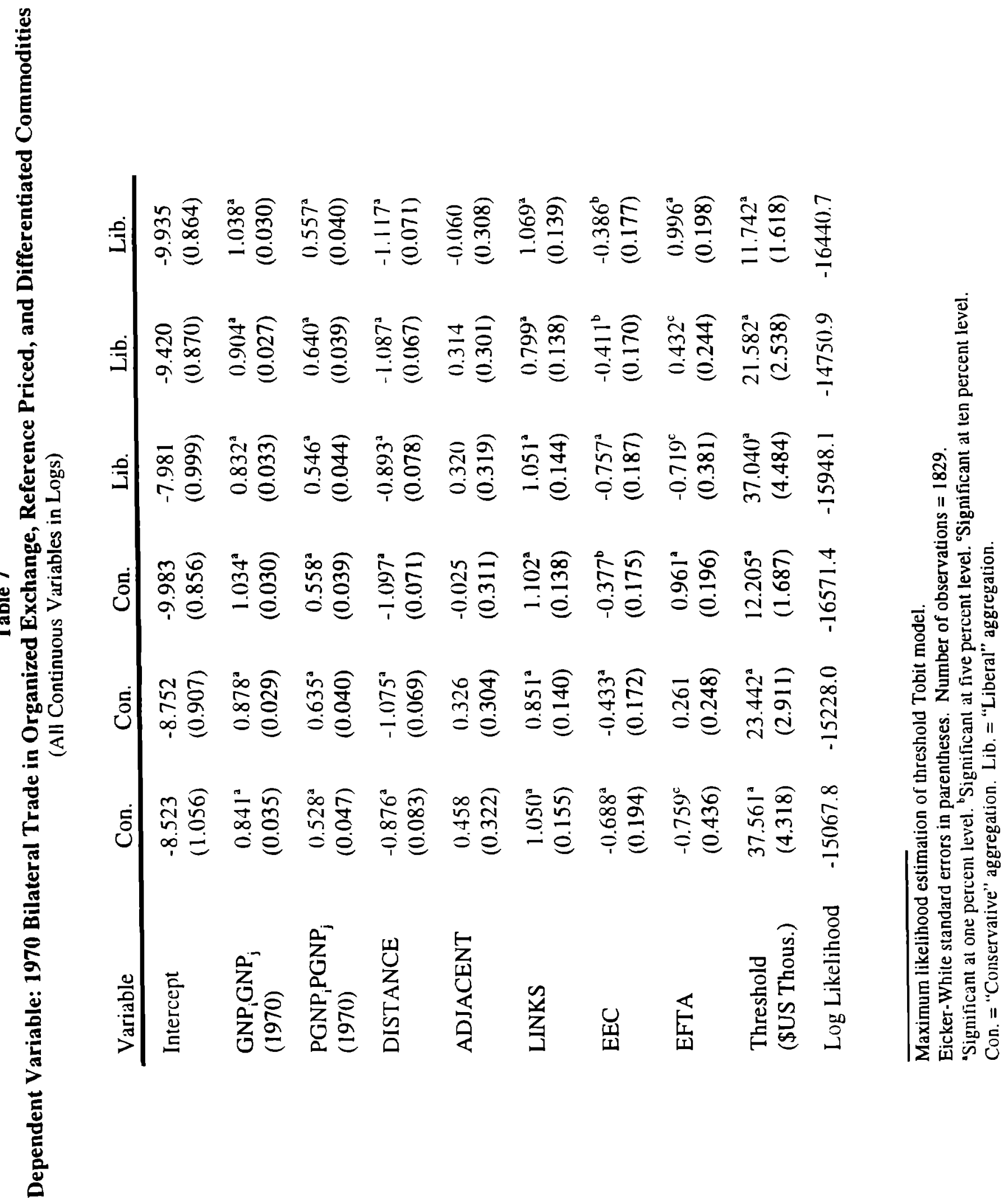




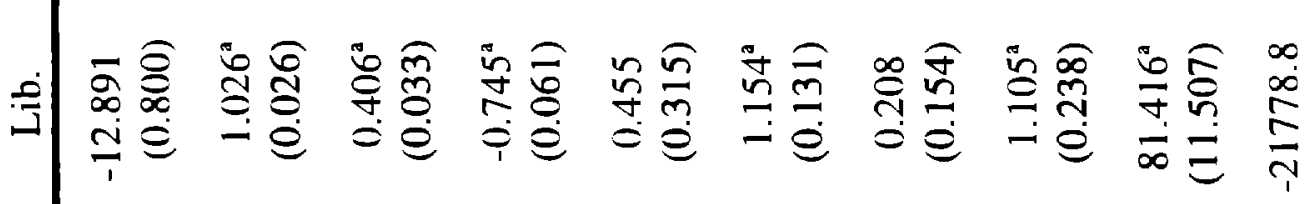

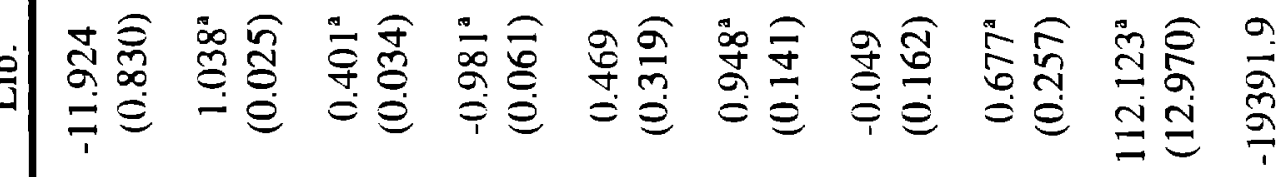

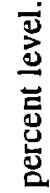

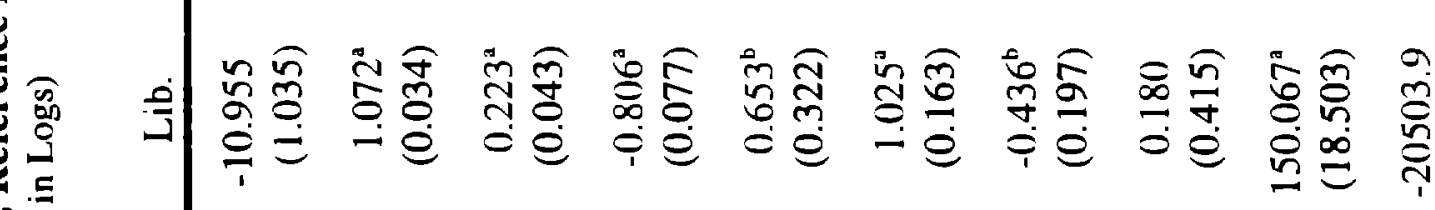

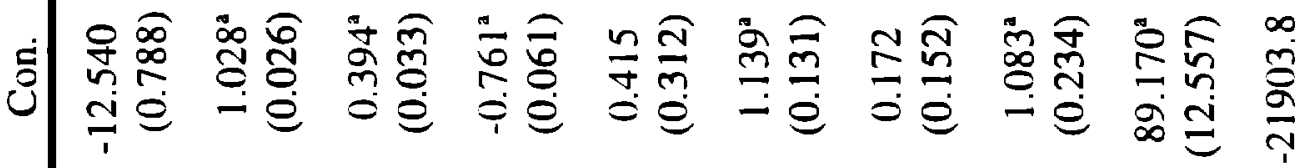

허 워

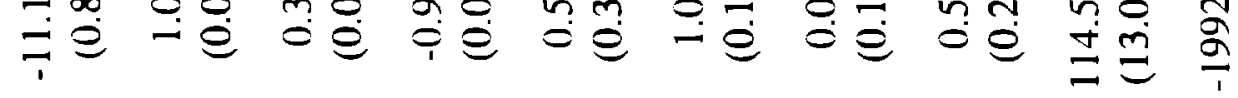

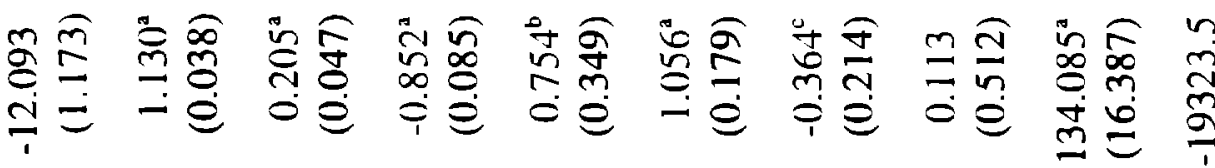

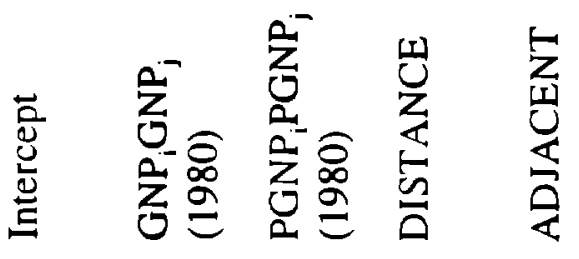

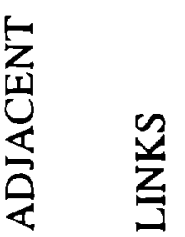

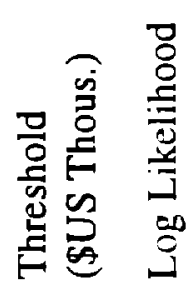

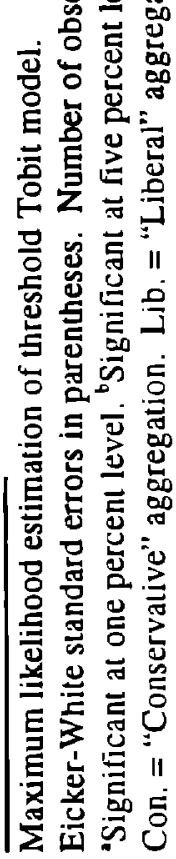




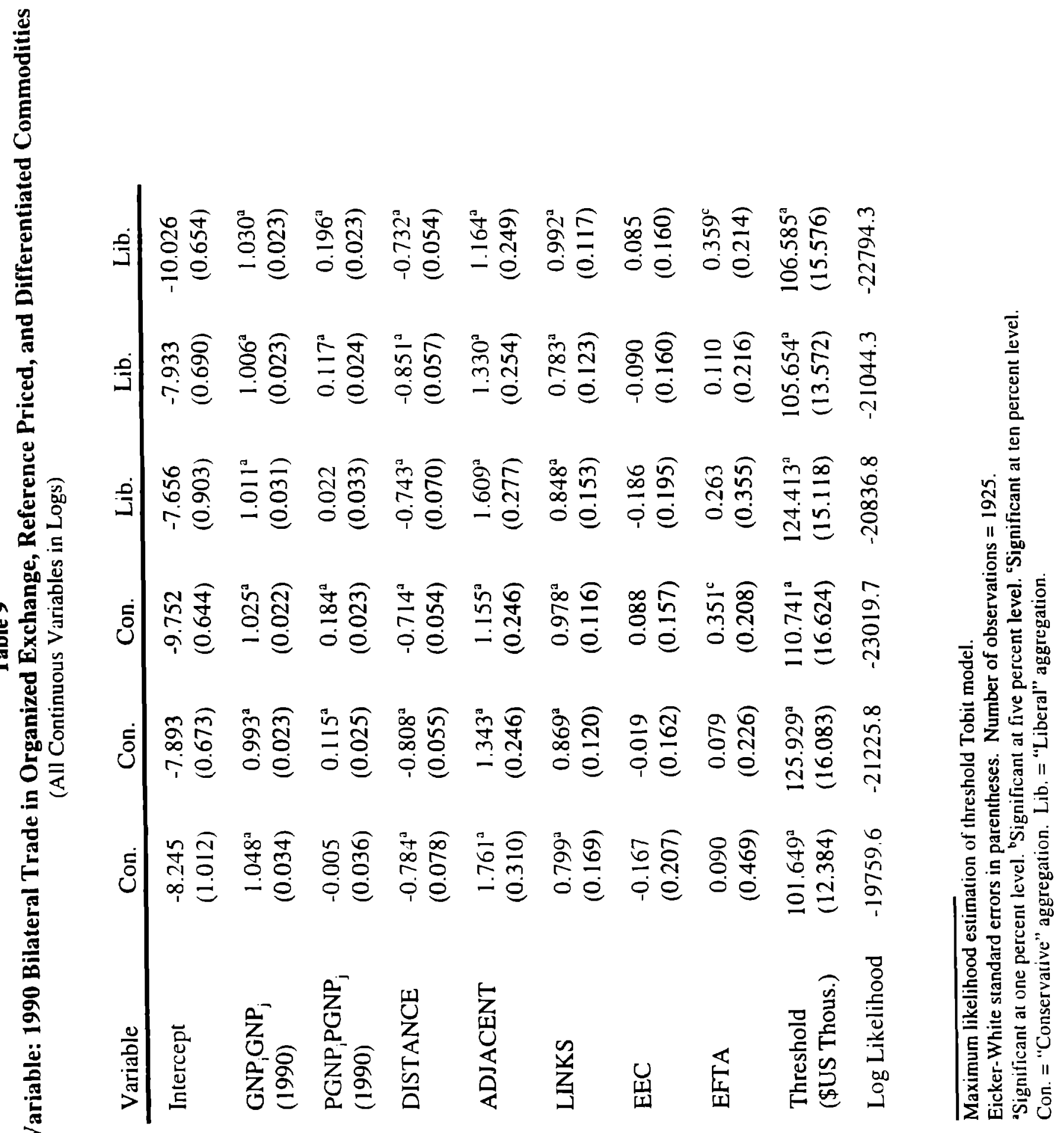




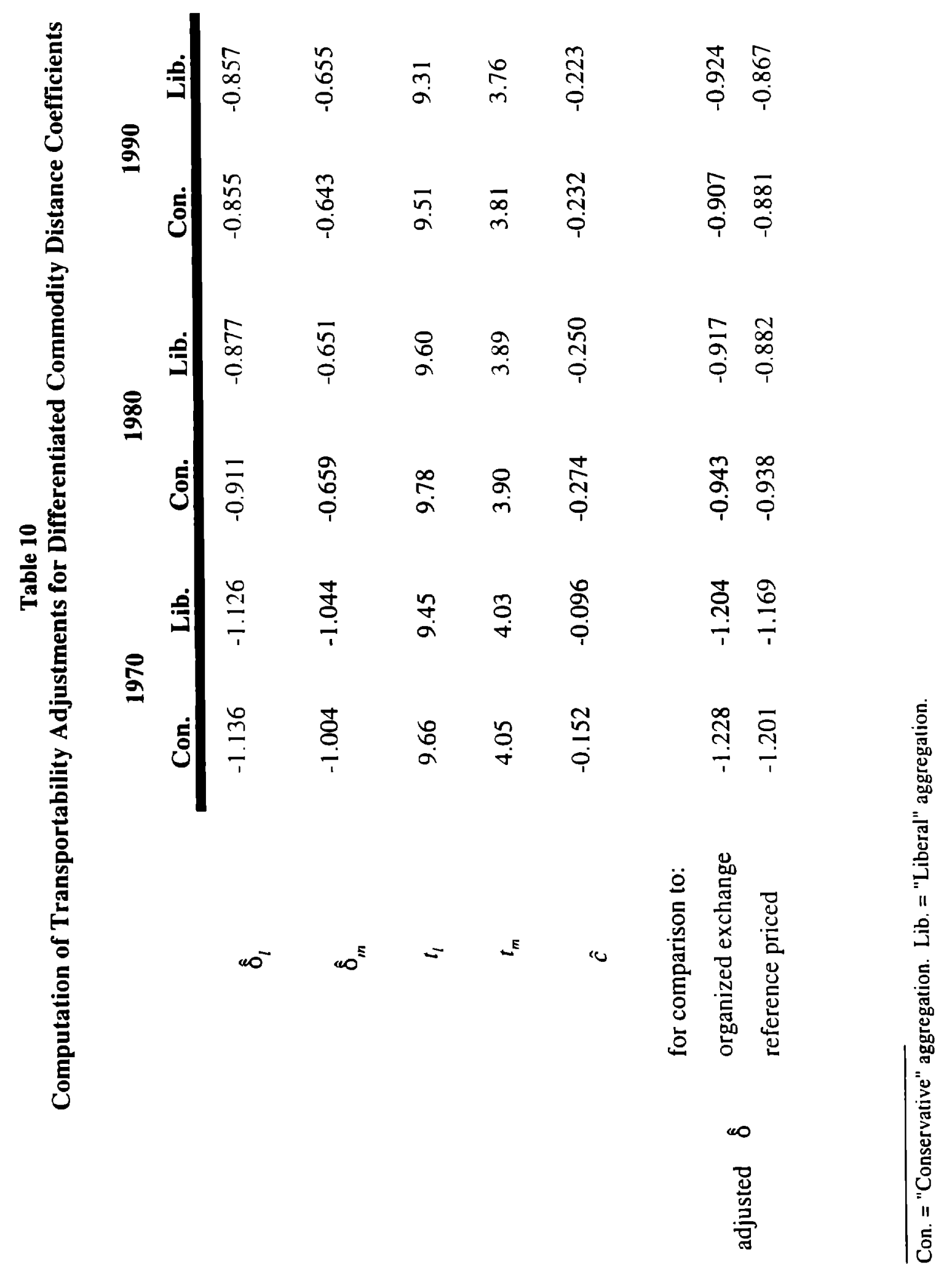



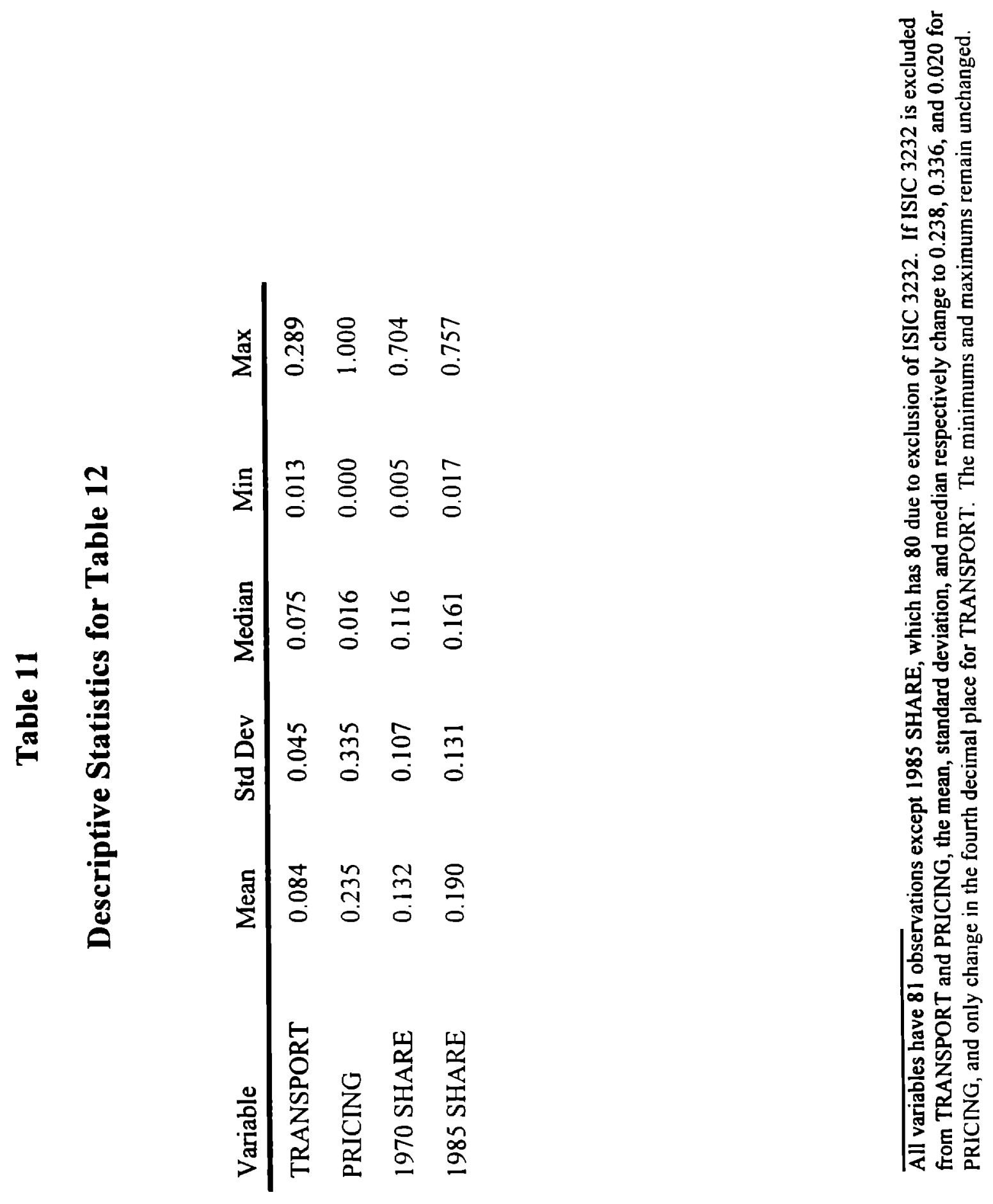


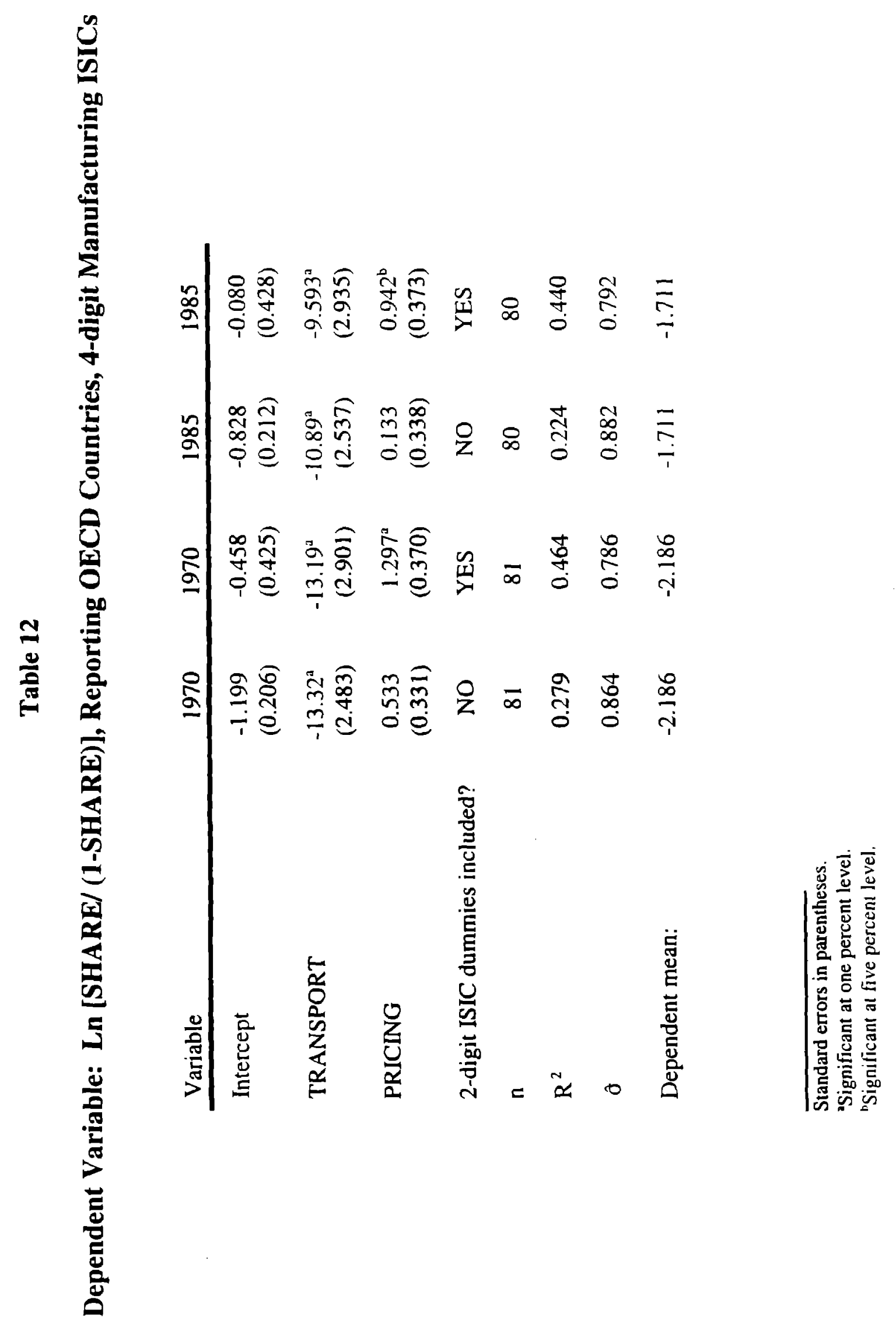

